[ CAROL GARCIA ]

Mestre e doutora em Comunicação e Semiótica pela

PUC-SP. Autora do livro Imagens errantes: ambiguidade,

resistência e cultura de moda e coautora de Moda é

comunicação: experiências, memórias, vínculos. Atualmente, pesquisa a migração de imagens entre culturas.

E-mail: mcarolinagarcia@uol.com.br

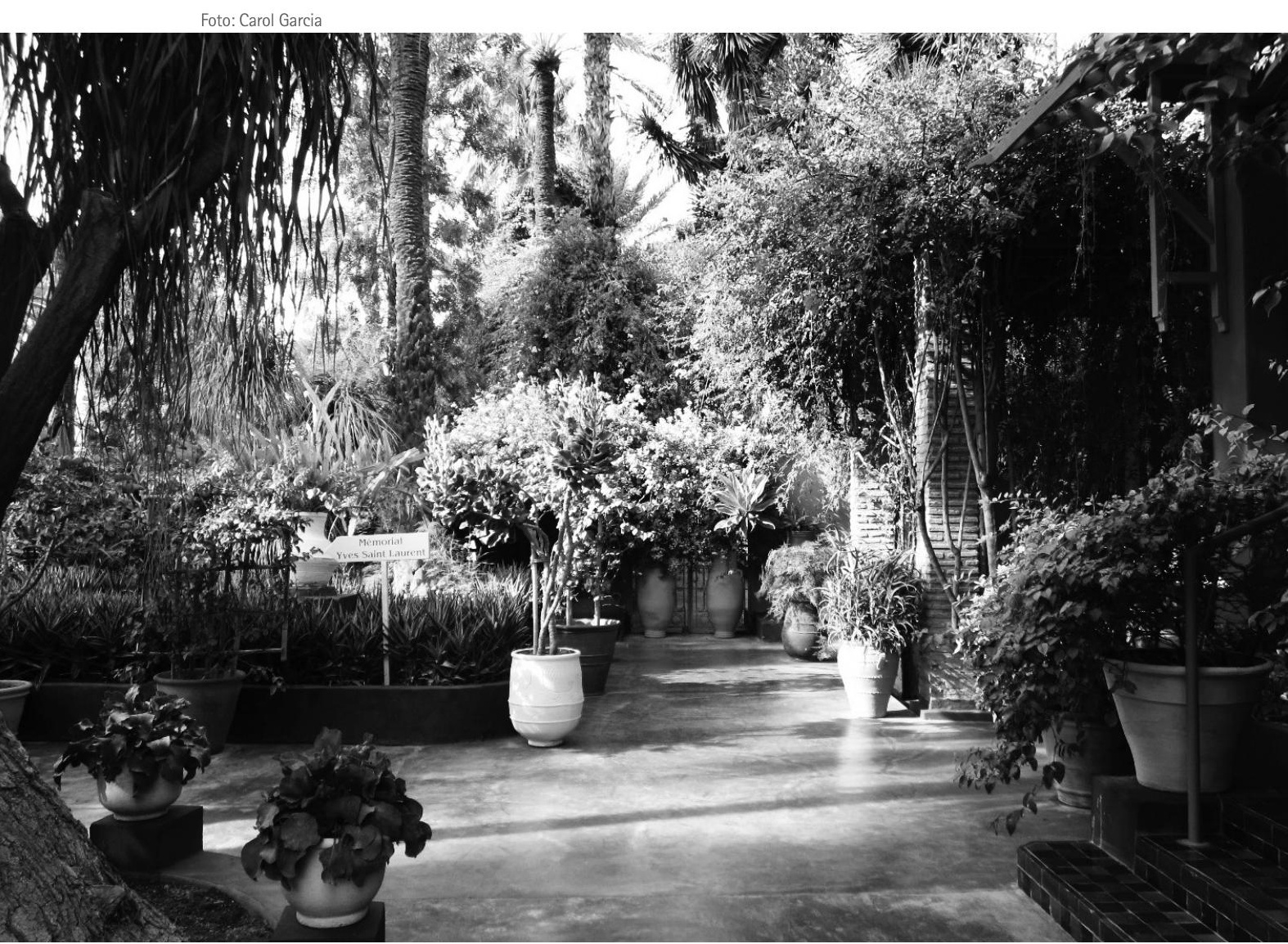

Trilhas imperdiveis no Jardin Majorelle.

\title{
Jardim das delícias
}

Primeiro estranha-se, depois entranha-se.

Fernando Pessoa

Bastou abrir a porta do trem para ser nocauteada. Nauseante e ocre, a força daquele cheiro penetrava pelos poros sem dó. Mesmo horas depois de tê-lo deixado para trás, assim como a poeirenta visão da estrada de ferro que liga Rabat, capital administrativa do reino do Marrocos, a Marrakech, centro do Império do Magreb, de Al-Andalus e de Yves Saint Laurent. Atravessei as muralhas avermelhadas da cidade em pleno Eid Al Adha, ${ }^{1}$ uma das duas grandes festividades islâmicas, com os dez miIhões de receptores olfativos de meu sistema nervoso em estado de alerta. Nessa data, celebrada em memória de Ibrahim, que teria aceitado sacrificar seu filho Ismael segundo uma ordem de Deus, todos os muçulmanos que possuem recursos econômicos devem sacrificar carneiros, camelos, bodes ou cabras para relembrar o acontecimento. A carne do animal é distribuída entre familiares, amigos e pessoas sem condições financeiras, celebrando a partilha e a caridade. Seu aroma, contudo, impregna-se nas paredes e na memória. Indelevelmente.

Em 2012, quando descobri o Eid Al Adha, as vielas espiraladas de Marrakech abrigavam cerca de um milhão de habitantes. Faça as contas e multiplique pelo calor acima de 40 graus Celsius para entender o impacto brutal dessa antiga celebração 
sobre narinas tão estrangeiras quanto as minhas. Cheiro de morte, mas também de sua antagonista mais suave, a vida, num daqueles embates semióticos sem trégua. Escondo-me no fundo do capuz da djellaba. ${ }^{2}$ Feriados como esse, presumo, devem ter inspirado os árabes a favorecer a difusão de fragrâncias, estabelecendo a perfumaria e o cultivo de jardins como uma de suas habilidades mais caras. Elevo meu pensamento às rosas, tentando dispersar a forte imagem olfativa. Segundo Fontanari (2008), os árabes foram os inventores do alambique (do árabe al-lanbiq), que fazia uso da serpentina de resfriamento, desenvolvida pelo alquimista Ibn-Sina, mais conhecido como Avicena (980-1073), também criador da primeira água de rosas do mundo. Avicena foi capaz de isolar o perfume das pétalas em óleo, um grande avanço na história da perfumaria, que culminou, na Idade Média, com o desenvolvimento de técnicas de destilação de plantas em larga escala. Essas mesmas técnicas estão presentes nos muitos frascos de perfumes que se amontoam nos souks, ${ }^{3}$ o comércio dos velhos tempos, onde a África encontra a Arábia. Um dos melhores representantes é precisamente o Arboriste Avicenne (Rahba Lakdima Souk Laghzel, 172-174), cujos óleos apresentam notas de laranja, musk, rosas e âmbar. Já entre os perfumistas, a descoberta é Les Parfums du Soleil, ${ }^{4}$ de Abderrazak Benchaabane, ${ }^{5}$ autor da fragrância Soir du Marrakech.

Para o bem e para o mal, portanto, não há como escapar de uma Marrakech feita de imagens olfativas, apesar das cores inebriantes que as portas desérticas da cidade imperial marroquina guardam para os viajantes mais atrevidos. Nas vielas da antiga Medina, os riads, ${ }^{6}$ belas mansões dos comerciantes de outrora, converteram-se em refúgios-boutique para que essa profusão de aromas, visões e texturas contrastantes faça da cidade a meca de aventureiros e designers. Todos em busca dessa arrebatadora montanha-russa de sentidos desde que Talitha Getty colocou-a no mapa hippie chic. Foi ela quem convenceu Yves Saint Laurent e Pierre Berger a conhecer Marrakech, isso na década de 1960. De lá para cá, definitivamente, a cidade converteu-se num ângulo agudo entre vida e morte, onde os extremos convivem com a certeza de que podem migrar rapidamente de um ponto a outro.

\section{A Marrakech de Saint Laurent}

Segundo Lelièvre (2011, p. 96), "Marrakech tem a mesma importância para 0 mito de Yves Saint Laurent que Saint-Tropez tem para o mito de Brigitte Bardot". Nas palavras do próprio criador:

- Em cada esquina podia-se cruzar com grupos de impressionante intensidade, relevo, homens e mulheres aos quais se misturam cafetãs cor-de-rosa, azuis, verdes, violeta. É surpreendente pensar que esses grupos, que parecem ter sido desenhados ou pintados, e evocam os esboços de Delacroix, são no fundo apenas a improvisação da vida conta Yves (LELIĖVRE, 2011, p. 98).

Apenas nove dias após sua chegada à cidade, reza a lenda, Saint Laurent comprou uma pequena casa no bairro árabe, Dar-el-Hanch, a Casa da Serpente, a alguns minutos da alucinante praça Djemaa el Fna. Nos mercados, ele garimpou objetos de cerâmica, esteiras, cestos de vime, louças de barro cozido, joias étnicas, roupas tradicionais marroquinas... Aprendeu os segredos das passamanarias, encantou-se pelos frascos de óleo de argan, extasiou-se com a delicadeza da água de rosas... De bicicleta ou com os amigos, passeou pelos jardins cultivados pelo pintor Majorelle, depois deixados ao abandono, e começou a enamorar-se de seus aromas quentes. Dez anos depois, Opium (1977) entrava num frasco para se tornar um ícone da perfumaria mundial, e Marrakech seguia tatuando a alma de Saint Laurent.

Nos anos 1980, já completamente envolvido pelas cores e aromas da cidade, Yves Saint Laurent criou nela uma das armadilhas para turistas mais convincentes e imperdíveis do mundo. Nessa ocasião, ele e o companheiro, Pierre Berger, adquiriram uma obra-prima da jardinagem, concebida por outro artista, o pintor francês Jacques Majorelle, e em seu miolo fundaram o Musée Berbère, organizando o acervo comprado ao longo de tantos anos nas vielas da cidade. Trata-se do Jardin Majorelle. Nele, os jardins árabes ganham sotaque francês e os aromas extremos de Marrakech explodem nos contrastes mais que exuberantes de cerca de 300 espécies de plantas. Lelièvre (2011, p. 98) ressalta: "Todas as sensações estocadas na memória do corpo expandem-se como uma flor de papel mergulhada na água". 
Lelièvre (2011, p. 101) nos conta ainda que, "(...) como quem não quer nada, Yves observa, analisa, examina, estoca imagens". Resolvi fazer o mesmo e deixar 0 Eid Al Adha no fundo da memória. Foi quando descobri, graças ao próprio estilista, que Marrakech é uma festa olfativa, de toques impressionistas e curvas generosas. 0 Jardin Majorelle, última morada do genial criador, está entre as pérolas de seu legado, assim como a rua onde se localiza. Ela é o berço do Herboriste Berbere (Rue Yves Saint Laurent, s/n), perfumaria célebre à entrada do jardim, assim como da loja-conceito mais interessante de Marrakech, cujo nome é o próprio endereço: 33, Jardin Majorelle. 0 espaço concentra criações dos jovens estilistas marroquinos e resolve o problema de viajantes que preferem não adentrar os souks (o que, em minha opinião, é puro desperdício). Mas é apenas uma parada. Para aqueles mais intrépidos, recomendo mais algumas, seguindo as trilhas imaginárias de Saint Laurent. A primeira é Chez Belhaj (Dar el Bacha Sidi Abdelaziz, 88), simpática fábrica de caftans onde, ao mencionar a palavra Brasil, a resposta não é Neymar, mas Adriana Bittencourt, já que a empresa se diz fornecedora da marca brasileira. A outra é Akbar Delights (Place Bab Fteuh), boutique-paraiso da cultura berbere com filial em Portofino, onde os tais caftans, embora desenhados em Marrakech, são, de fato, fabricados na Índia. E a terceira é L'Ourika Caftan (Daffa Warbaa, 77), provedora de bordados para 0 próprio Saint Laurent e, posteriormente, também para Giorgio Armani. Gosto ainda do cantinho de criadores no primeiro andar da galeria em que se encontra o mágico restaurante Terrasse des Épices (Souk Cherifia, 15), onde os aromas do Jardin Majorelle se encontram com os sabores da inconfundivel Marrakech. Pausa para respirar e novos segredos para descobrir.

\section{VISITE}

Jardin Majorelle

Rue Yves Saint Laurent, s/n | +212 (0) 524313047 | Marrakech | Marrocos

www.jardinmajorelle.com

\section{NOTAS}

[1] 0 Eid Al Adha marca o fim do Hajj, a peregrinação a Makkah, e acontece no décimo dia do último mês do calendário islâmico, o Dhul Hijjah.

${ }^{[2]}$ Djellaba, segundo me explica a antropóloga Maria Angela Jansen, idealizadora da Non Western Dress Conference (precisamente o evento que me levou a Rabat para uma conferência no Centre Jacques Berque, em 2012), pode ser considerada a veste que representa a liberação feminina no Marrocos. Isso porque teria sido idealizada para que as meninas pudessem ir à escola, ou seja, frequentar espaços públicos, sem ferir as leis muçulmanas. Esse traje consiste numa veste retangular longa, com mangas compridas e um imenso capuz para proteger os cabelos e também parte do rosto.

${ }^{[3]}$ Há séculos, os souks, dispersos pelo grande Mercado de Djemma el Fna, configuram um espaço de troca tipicamente norte-africano, voltado para visitantes de cidades subsaarianas e navegantes espanhóis. Divididos por áreas (metais, couros, têxteis, perfumes), exigem do visitante total subserviência e narinas treinadas para seguir odores ora fétidos, ora deliciosos. Ervas e flores, muitos cultivados aos pés das montanhas Atlas, são comercializados por mercadores berberes, herboristas natos.

${ }^{[4]}$ Disponivel em: <www.lesparfumsdusoleil.com>. Acesso em: 23 jul. 2013.

${ }^{[5]}$ Abderrazak Benchaabane foi responsável, ao lado do amigo Yves Saint Laurent, pela restauração do Jardin Majorelle e, posteriormente, fundou uma casa de perfumes que evoca o próprio jardim.

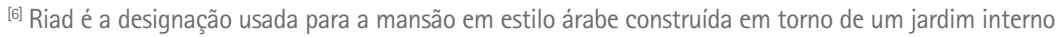
dentro das muralhas da cidade antiga e geralmente habitada por familias grandes.

[7] Em sua viagem de núpcias ao Marrocos, a modelo Talitha Getty e o marido Paul Júnior compraram uma casa do século XIX em Marrakech, o palácio de Zahia, que rebatizaram de Palácio dos Prazeres. Ali foi tirada a célebre foto de Patrick Lichfield para a Vogue americana na qual Talitha praticamente levita num caftan marroquino, imortalizando o look beldi no Ocidente (LELIEVRE, 2011, p. 97).

[8] "(...) Em 1967, o Marrocos é o novo destino do jet set hippie, seduzido pelos relatos de viagem de escritores da geração beat, como Allen Ginsberg, Jack Kerouac, William Burroughs, que descobrem o país graças ao amigo Paul Bowles, estabelecido em Tanger" (LELIĖVRE, 2011, p. 96).

\section{REFERÊNCIAS}

FONTANARI, J. R. A imagem do cheiro: o paradoxo na publicidade do perfume. São Paulo, 2008. Dissertação (Mestrado em Comunicação e Semiótica) - Pontificia Universidade Católica de São Paulo. 